\title{
High Pressure Falling Sinker Liquid Viscosity Determination without Supplementary Density Data: A New Approach
}

\author{
Minyu Zeng and Carl Schaschke \\ Department of Chemical and Process Engineering, University of Strathclyde, 75 Montrose Street, Glasgow G1 1XJ, UK \\ Correspondence should be addressed to Carl Schaschke, carl.schaschke@strath.ac.uk
}

Received 17 June 2009; Accepted 26 October 2009

Recommended by Mostafa Barigou

\begin{abstract}
Accurate measurement and determination of liquid viscosity data under high pressure conditions requires knowledge of liquid density data. In this study, a high pressure falling sinker-type viscometer was used to determine the viscosity of $\mathrm{n}$-dodecane at elevated pressures up to $132 \mathrm{MPa}$ without supplementary knowledge of liquid density. The viscometer, which involves the downward movement of a cylindrical sinker under the influence of gravity through the liquid contained within a closed tube, avoided the need for density data by repeating the sinker-timing experiments with two geometrically similar but different-sized sinkers thereby allowing the liquid density in the associated formulae to be eliminated. Furthermore, it was possible to subsequently derive liquid density. Both viscosity and density data were compared to published data for which good correlation was found for viscosity. To minimize errors, it is suggested that the two sinkers for such an approach should be of sufficiently differing densities.
\end{abstract}

Copyright ( $) 2009$ M. Zeng and C. Schaschke. This is an open access article distributed under the Creative Commons Attribution License, which permits unrestricted use, distribution, and reproduction in any medium, provided the original work is properly cited.

\section{Introduction}

The viscosity of liquids is an important property in fluid flow and the estimation of other physical properties such as in the estimation of diffusion in liquid systems [1]. Accurate data is therefore required for many applications in engineering design. The high pressure falling body viscometer is a simple and effective device for the accurate measurement of viscosity for liquids over a wide range of viscosities [2-12]. Consisting of a vertically positioned closed tube, a cylindrical sinker is allowed to descend at terminal velocity under the influence of gravity through a liquid under investigation. The viscosity is readily determined from the time for the sinker to descend a known distance and the physical details of the viscometer. However, under very high pressure conditions, the calculations are not so straightforward as liquids may not be assumed to be incompressible since density data is required to complete the viscosity calculations. Where experimental data may not be available, published experimental data may be available; predictive approaches based on critical point data or multiparameter corresponding states methods may be used for many pure fluids and some mixtures [13-16]. For many complex fluids and mixtures such as automotive fluids, liquid foods and mixtures such as biodiesels, density data may, however, not be available [17]. Although the critical point data can be predicted in some cases, this can lead to complication and mathematical uncertainty which can significantly influence the determined viscosity data. The resulting error in the data may be correspondingly very significant thus rendering it unreliable for good scientific and engineering purposes. To overcome the need for compressibility data for liquids at high pressure, we examined the use of two geometrically similar sinkers to determine liquid viscosity as a way of overcoming the need for supporting density data.

\section{Falling Body Viscometer}

The high-pressure viscometer used in this work was based on the falling sinker design. Designed and fabricated by the National Engineering Laboratory (NEL) in East Kilbride, UK, the viscometer consists of a vertical tube containing a test liquid through which the sinker falls freely under the influence of gravity (Figure 1). The rate of descent of the sinker which falls concentrically is related to the displacement of liquid and frictional effects in the annular 


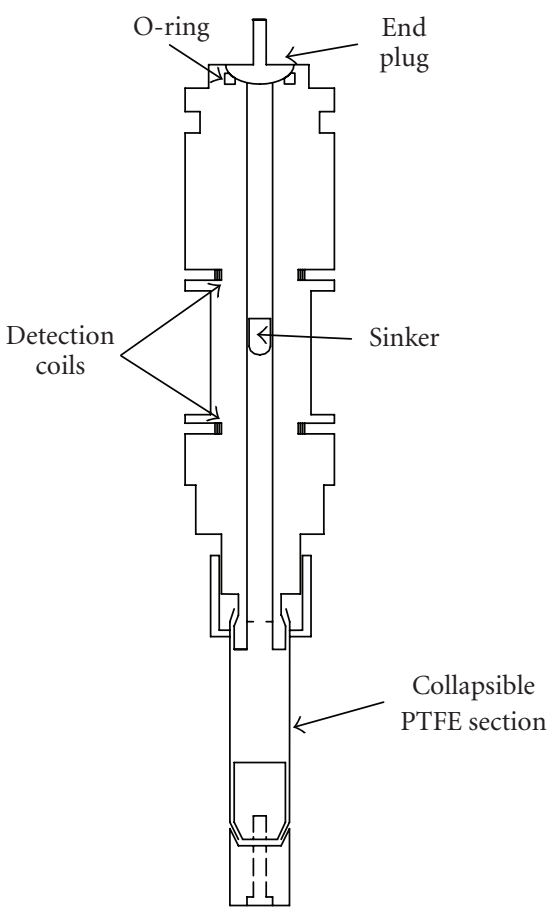

FIGURE 1: Viscometer tube and sinker.

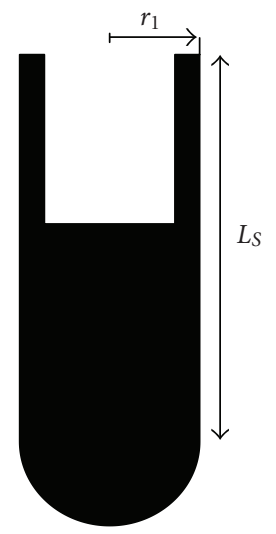

Figure 2: General design of a sinker.

region between the tube and the sinker. As the sinker descends, the liquid is displaced upwards forcing it to pass through the annular gap between the walls of the tube and the sinker.

The sinker and the tube are fabricated from a solid bar of nonmagnetic stainless steel to minimise compressibility and thermal expansion effects. Designed to be self-centring, the sinker used has a cylindrical body with a hemispherical nose embedded with a ferrite core (Figure 2). Ratios of sinker to inner tube radii in excess of 0.95 are required for the sinker to descend concentrically within the tube. Sinkers which fall eccentrically are well known to cause significant errors [18, 19].

The viscosity is determined directly from the time taken for the sinker to descend a fixed distance. In this case, this is the distance between two detection coils wrapped around

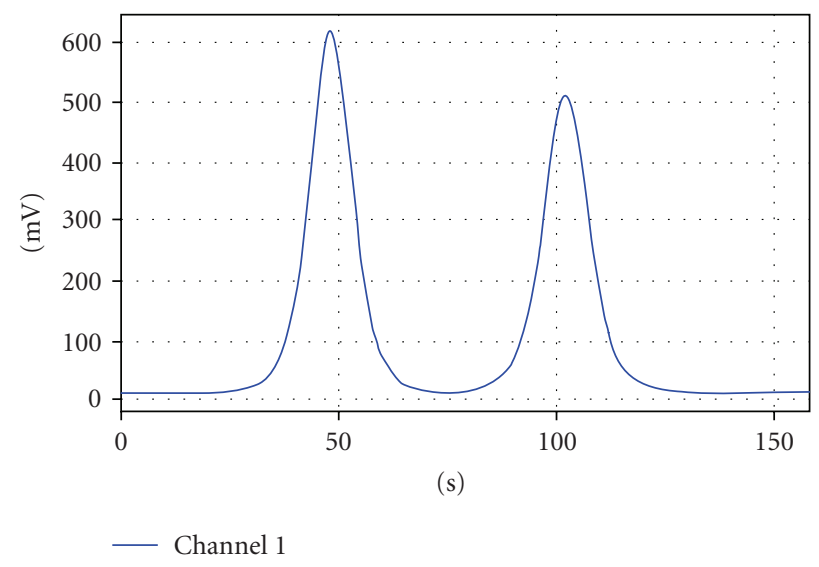

FIGURE 3: Signal response for sinker movement between detection coils.

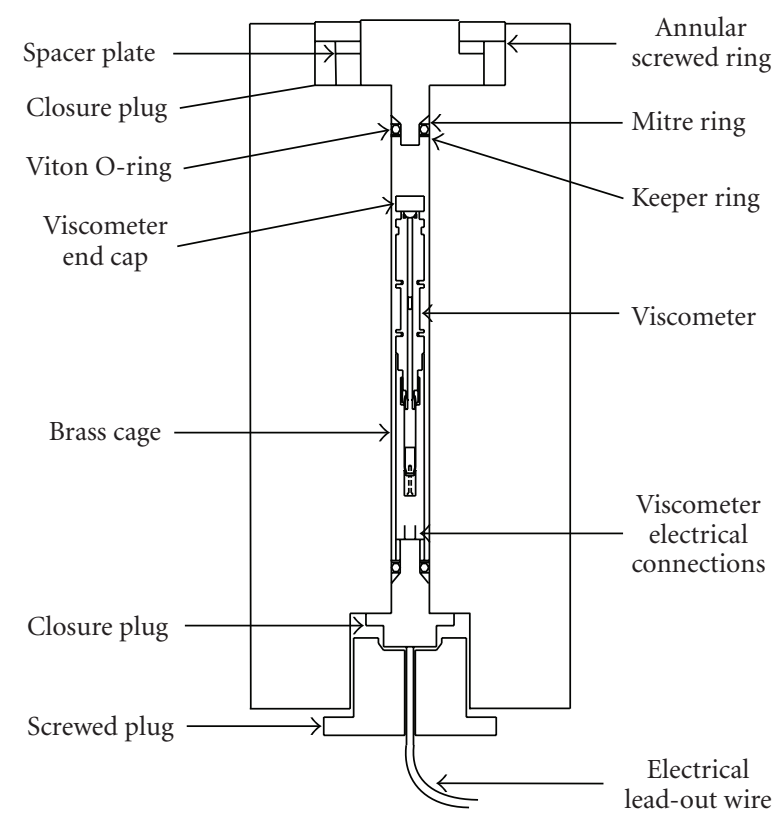

FIGURE 4: High pressure vessel with falling sinker viscometer tube.

the outside of the tube with the location of the sinker being detected by the change in inductance in the coils. The coils are set a distance of $12 \mathrm{~mm}$ apart and consist of around 200 turns of lacquered copper wire, each with approximately equal electrical resistance, and both forming the active arm of a balanced bridge circuit. The out-of-balance signal from the bridge is amplified and passed through an AC/DC converter to give a DC signal which increases to a maximum when the ferrite core of the sinker is positioned at the centre of the coil (Figure 3). From the dimensions of the viscometer tube and sinker, and the time for the sinker to fall freely with terminal velocity between two points, the viscosity can be determined.

Samples of $\mathrm{n}$-dodecane oil were sealed into the tube using a shrinkable PTFE expansion sheath. It was essential that neither air nor particles remained entrapped with the sample which could influence the rate of sinker descent. 
The tube and associated assembly was housed in a highpressure vessel and maintained at a constant temperature by air circulation (Figure 4). The pressure is transmitted in the oil through the flexible PTFE sheath using a paraffin/Shell Tellus oil mixture as the hydraulic medium by pressure amplification to a maximum possible operating pressure of $500 \mathrm{MPa}$. This mixture offers good lubricating properties with a low freezing point. The entire high pressure vessel itself is mounted on bearings and rotated $180^{\circ}$ to return the sinker to its original starting position between each measurement. A calibrated Kistler piezo-resistive pressure gauge, type $46180 \mathrm{~A}$ and calibrated to $500 \mathrm{MPa}$, was used to measure the high pressure within the viscometer tube.

\section{Analysis}

The rate of descent of a sinker in a closed tube is based on a force balance of gravity, buoyancy and resistive shear forces with fully developed laminar flow and has been previously shown $[20,21]$ in which the viscosity can be expressed in the form

$$
\mu=\frac{\left(1-\left(\rho_{f} / \rho_{s}\right)\right) t}{A\left(1+2 \alpha\left(T-T_{o}\right)\right)\left(1-2 / 3 \beta\left(P-P_{o}\right)\right)},
$$

where

$$
A=\frac{2 \pi L_{s O} L_{t O}}{m_{s} g\left(\ln \left(r_{2} / r_{1}\right)-\left(\left(r_{2}^{2}-r_{1}^{2}\right) /\left(r_{2}^{2}+r_{1}^{2}\right)\right)\right)} .
$$

The thermal expansion coefficient and compressibility of the sinker are small $\left(7.6 \times 10^{-6} \mathrm{~K}^{-1}\right.$ and $3.075 \times 10^{-6} \mathrm{MPa}^{-1}$, resp.) and can thus be ignored. In contrast, small measurement errors in radii $r_{1}$ and $r_{2}$ result in significant errors; the effects of which have been studied by Wehbeh et al. [22] Ideally, the coefficient A is based on the physical dimensions of the sinker as shown. In practice, however, there is often a deviation in viscosity determined experimentally due to wall and end effects [23-26]. The coefficient A is therefore adjusted using a calibration liquid of known properties under high pressure [27]. To confirm the cause of these deviations 2D and 3D CFD studies have previously shown the presence of vortices shedding from the trailing edge of the sinker. The simulations have shown that fully developed laminar flow is not met within the annual gap $[21,28]$. It has, however, been confirmed that coefficient A tends towards the theoretical value for a modified Reynolds numbers below 60 [18], where

$$
\operatorname{Re}_{m}=2 r_{1}^{2} \frac{\rho_{f} v}{\left(r_{1}+r_{2}\right) \mu} .
$$

For two geometrically similar sinkers tested in the same liquid at the same temperature and pressure, the density of the liquid can be deduced to be

$$
\rho_{f}=\frac{\rho_{s 1} \rho_{s 2} A_{2} t_{1}-\rho_{s 1} \rho_{s 2} A_{1} t_{2}}{\rho_{s 2} A_{2} t_{1}-\rho_{s 1} A_{1} t_{2}} .
$$

Likewise, for the two sinkers, the viscosity is obtained from

$$
\mu=\frac{\rho_{s 2} t_{1} t_{2}-\rho_{s 1} t_{1} t_{2}}{\rho_{s 2} A_{2} t_{1}-\rho_{s 1} A_{1} t_{2}} .
$$

To determine both the viscosity and density, this may be possible for two measurable and distinguishable values of $\mathrm{A}$ and sinker descent times.

\section{Materials and Methods}

In this work, n-dodecane with a purity greater than $99 \%$ purchased from VWR International Ltd, UK was used as the test liquid. The properties of $n$-dodecane have been previously reported [29].

4.1. Density. The density data was based on using a Tait-type equation of the form

$$
\rho_{f}=\rho_{o}\left(1-C \log _{10}\left(\frac{B+P}{B+P_{o}}\right)\right)^{-1}
$$

in which

$$
\begin{gathered}
\rho_{o}=\sum_{i=0}^{2} a_{i} T^{i}, \\
B=\sum_{i=0}^{2} b_{i} T^{i} .
\end{gathered}
$$

4.2. Viscosity. The viscosity was found from

$$
\mu=\mu^{*}\left(4.779 \times 10^{-9} V^{-2 / 3} M^{1 / 2} T^{1 / 2}\right)
$$

for which the dimensionless viscosity was calculated from

$$
\mu^{*}=\frac{1}{\sum_{i=0}^{3} d_{i}\left(V / V_{o}\right)^{i}},
$$

where the core volume is dependent on the absolute temperature in the form

$$
V_{o}=\sum_{i=0}^{3} e_{i} T^{i}
$$

The parameters are given in Table 1.

\section{Sinker Selection}

To determine the viscosity without supplementary density data, it is important to select sufficiently different sized but geometrically similar sinkers. There are certain other criteria that must also be fulfilled in this selection process. In particular, the sinker is required to be self-centering during descent. The time for descent for the two sinkers is also required to be appreciably different, for which the time for descent is

$$
t=\frac{A \mu}{1-\left(\rho_{f} / \rho_{s}\right)} .
$$

It is worth noting that since the density of most liquids does not increase significantly with pressure then as the pressure increases large values of A contributes to longer descent 
TABle 1: Parameters.

\begin{tabular}{lc}
\hline Coefficient & Value \\
\hline$a_{0}$ & 921.984 \\
$a_{1}$ & -0.47516 \\
$a_{2}$ & $-3.922 \times 10^{-4}$ \\
$b_{0}$ & 345.1 \\
$b_{1}$ & -1.1458 \\
$b_{2}$ & $0.9837 \times 10^{-3}$ \\
$C$ & 0.2072 \\
$d_{0}$ & 0.321621 \\
$d_{1}$ & -0.480372 \\
$d_{2}$ & 0.222206 \\
$d_{3}$ & $-2.964626 \times 10^{-2}$ \\
$e_{0}$ & 191.54 \\
$e_{1}$ & -0.441338 \\
$e_{2}$ & $8.98744 \times 10^{-4}$ \\
$e_{3}$ & $-6.7792 \times 10^{-7}$ \\
$\mathrm{M}\left(\mathrm{kg} \cdot \mathrm{mol}^{-1}\right)$ & 0.17034 \\
\hline
\end{tabular}

time. Conversely, similar values for A imply the need for appreciably different sinker densities. The details of the two sinkers used in this study are given in Table 2.

For both sinkers used in this study, readings for the time for sinker descent were recorded over a pressure range of $0.1 \mathrm{MPa}$ to $132 \mathrm{MPa}$. Above this applied pressure, the sinker was not found to descend. This may have been due to a pressure-induced phase change. This phenomenon is found in certain liquids including hydrocarbons and lipids. All readings were repeated in triplicate.

\section{Results}

The sinker fall times for both sinkers are shown in Figure 5. This shows a rising increase in time with increasing applied pressure up to $132 \mathrm{MPa}$. Beyond this pressure, the sinker failed to descend. The modified Reynolds number for both sinkers at these pressures is shown in Figure 6. For both sinkers, the experimental coefficients A tends towards a constant value for which the average values were found to be $16122.5 \mathrm{~Pa}^{-1}\left(\sigma_{n-1}=320.2 \mathrm{~Pa}^{-1}\right)$ for sinker 1 while for sinker 2, A was $4062.6 \mathrm{~Pa}^{-1}\left(\sigma_{n-1}=56.0 \mathrm{~Pa}^{-1}\right)$. For comparison, the values for A calculated from the dimensions of sinker and tube are $16575.5 \mathrm{~Pa}^{-1}$ and $3890.7 \mathrm{~Pa}^{-1}$, respectively (Table 2), and are equivalent to a zero modified Reynolds number. While the two experimental and theoretical values are reasonably close, it should be noted that differences exist due to inaccuracies in measurement as well as end effects during sinker descent described earlier. Table 3 presents the sinker fall data and coefficients for the same applied pressures.

The deviation of evaluated viscosity and density data is presented in Table 4 and Figures 7 and 8.

Using this new approach, the determined viscosity data is comparable to that of Caudwell et al. [29]. The source of the errors obtained can be attributed to the variation of the

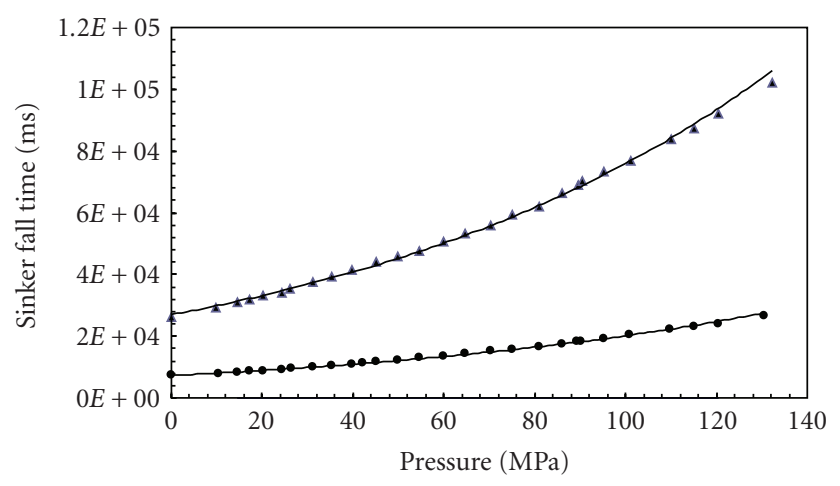

Figure 5: Sinker fall times. $\Delta$ sinker 1; • sinker 2.

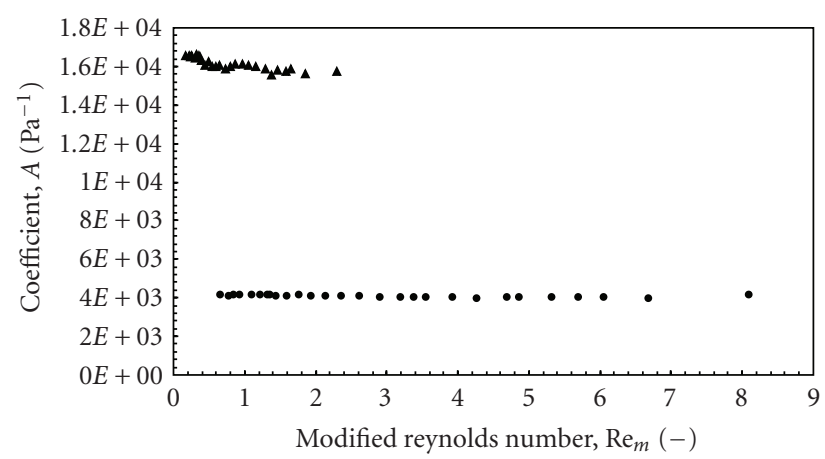

FIGURE 6: Variation of coefficients A for both sinkers modified reynolds number. $\boldsymbol{\Delta}$ sinker $1 ; \bullet$ sinker2.

coefficient A for which a summary of the errors is presented in Table 5.

\section{Error Transfer Analysis}

Although the error transfer analysis can be used to identify parameters other than A which are able to reduce the error caused by the coefficient in density determination, it is worth noting that the errors in both calibration coefficients may be of significance. In this analysis, the errors are assumed to be associated with both coefficients $\mathrm{A}_{1}$ and $\mathrm{A}_{2}$. In general, by assuming an error $\triangle \mathrm{R}$ on the final parameter $\mathrm{R}$ for which

$$
R+\Delta R=f\left(u_{1}+\Delta u_{1}, u_{2}+\Delta u_{2}, \ldots, u_{n}+\Delta u_{n}\right)
$$

then using Taylor's series expansion with only first order terms, the error can be given in the form:

$$
\begin{aligned}
R+\Delta R= & f\left(u_{1}, u_{2}, \ldots, u_{n}\right) \\
& +\left(\frac{\partial R}{\partial u_{1}} \Delta u_{1}+\frac{\partial R}{\partial u_{2}} \Delta u_{2}+\cdots+\frac{\partial R}{\partial u_{n}} \Delta u_{n}\right)
\end{aligned}
$$

for which the relative error term is thus

$$
\frac{\Delta R}{R}=\frac{\partial \ln R}{\partial u_{1}} \Delta u_{1}+\frac{\partial \ln R}{\partial u_{2}} \Delta u_{2}+\cdots+\frac{\partial \ln R}{\partial u_{n}} \Delta u_{n} .
$$


TABLE 2: Sinker details.

\begin{tabular}{lccccccc}
\hline Sinker & $\begin{array}{c}\text { Diameter } \\
(\mathrm{mm})\end{array}$ & $\begin{array}{c}\text { Radius } \\
(\mathrm{mm})\end{array}$ & $\begin{array}{c}\text { Length } \\
(\mathrm{mm})\end{array}$ & $\begin{array}{c}\text { Mass } \\
(\mathrm{mg})\end{array}$ & $\begin{array}{c}\text { Density } \\
\left(\mathrm{g} \cdot \mathrm{cm}^{-3}\right)\end{array}$ & $\begin{array}{c}\mathrm{A} \\
\left(\mathrm{Pa}^{-1}\right)\end{array}$ & $\begin{array}{c}\text { Radius Ratio } \\
(\text { Sinker/Tube })\end{array}$ \\
\hline 1 & 7.56 & 3.78 & 10.44 & 2976.2 & 7.3865 & 16575.5 & 0.977 \\
2 & 7.42 & 3.71 & 10.55 & 2218.8 & 5.0436 & 3890.7 & 0.959 \\
\hline
\end{tabular}

TABLE 3: Summary of experimental data for sinkers 1 and 2.

\begin{tabular}{lcccc}
\hline $\begin{array}{l}\text { Pressure } \\
(\mathrm{MPa})\end{array}$ & $\begin{array}{c}t_{1} \\
(\mathrm{~ms})\end{array}$ & $\begin{array}{c}t_{2} \\
(\mathrm{~ms})\end{array}$ & $\begin{array}{c}A_{1} \\
\left(\mathrm{~Pa}^{-1}\right)\end{array}$ & $\begin{array}{c}A_{2} \\
\left(\mathrm{~Pa}^{-1}\right)\end{array}$ \\
\hline 14.5 & 31136.5 & 8262.0 & 15865.0 & 3985.9 \\
20.3 & 33089.3 & 8862.3 & 15809.4 & 4007.9 \\
24.3 & 34035.3 & 9313.5 & 15567.1 & 4031.3 \\
31.2 & 37699.5 & 9914.5 & 15999.8 & 3980.7 \\
35.2 & 39479.5 & 10365.0 & 16064.7 & 3989.3 \\
39.7 & 41547.3 & 10966.0 & 16137.4 & 4027.9 \\
45.2 & 43901.4 & 11590.3 & 16107.8 & 4020.5 \\
49.9 & 45782.2 & 12167.0 & 16010.5 & 4021.9 \\
54.5 & 47537.5 & 12918.8 & 15873.9 & 4076.9 \\
59.8 & 50676.0 & 13653.0 & 16057.9 & 4087.7 \\
64.8 & 53082.5 & 14337.0 & 16013.9 & 4085.9 \\
70.4 & 56012.0 & 15072.0 & 16015.3 & 4070.2 \\
75.0 & 59309.2 & 15923.0 & 16225.5 & 4113.5 \\
81.0 & 62082.2 & 16674.0 & 16034.1 & 4065.7 \\
85.9 & 66225.2 & 17626.0 & 16337.6 & 4104.5 \\
95.2 & 73365.0 & 19352.5 & 16592.9 & 4130.2 \\
115.1 & 87317.5 & 23133.0 & 16481.6 & 4117.6 \\
120.5 & 91955.0 & 24186.3 & 16541.9 & 4102.3 \\
\hline & & & &
\end{tabular}

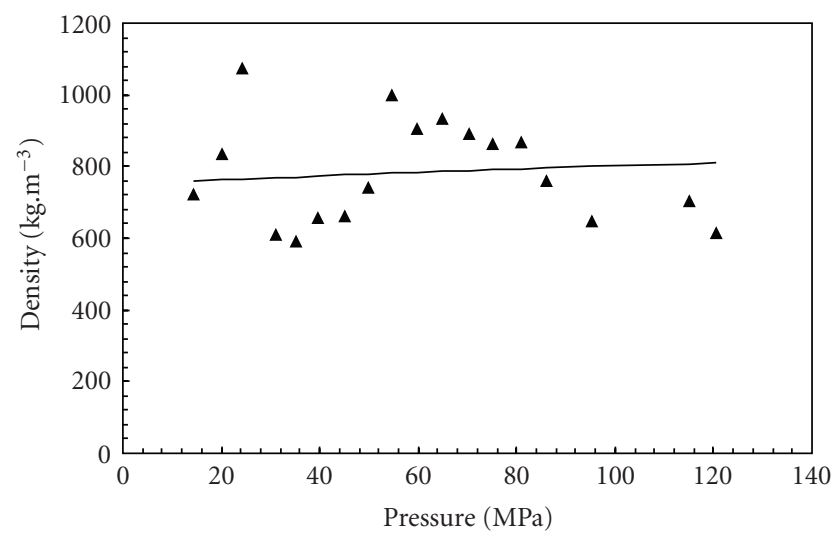

Figure 7: Deviation of evaluated density $(\boldsymbol{\Delta})$ with literature data (一) for n-dodecane.

7.1. Density. Based on the above, the relative error in density evaluation can be written as

$$
\frac{\Delta \rho_{f}}{\rho}=\frac{\partial \ln f\left(A_{1}, A_{2}\right)}{\partial A_{1}} \Delta A_{1}+\frac{\partial \ln f\left(A_{1}, A_{2}\right)}{\partial A_{2}} \Delta A_{2}
$$

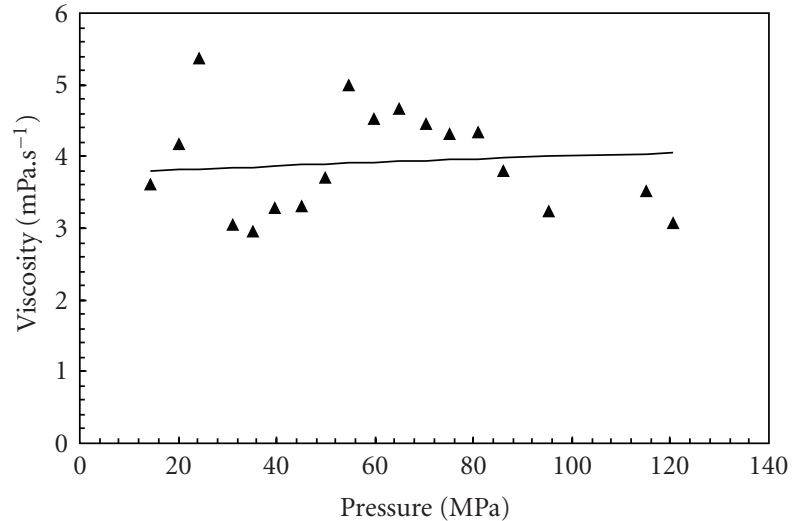

Figure 8: Viscosity Data for n-Dodecane. $\boldsymbol{\Delta}$ Experimental data, Caudwell et al. [29].

in which

$$
\begin{aligned}
& \frac{\partial \ln f\left(A_{1}, A_{2}\right)}{\partial A_{1}}=\frac{A_{2} t_{1} t_{2}\left(\rho_{s 1}-\rho_{s 2}\right)}{\left(A_{1} t_{2} \rho_{s 1}-A_{2} t_{1} \rho_{s 2}\right)\left(A_{1} t_{2}-A_{2} t_{1}\right)}, \\
& \frac{\partial \ln f\left(A_{1}, A_{2}\right)}{\partial A_{2}}=\frac{-A_{1} t_{1} t_{2}\left(\rho_{s 1}-\rho_{s 2}\right)}{\left(A_{1} t_{2} \rho_{s 1}-A_{2} t_{1} \rho_{s 2}\right)\left(A_{1} t_{2}-A_{2} t_{1}\right)} .
\end{aligned}
$$

Using $x$ to represent the relative error for the corresponding coefficient value of sinker, the error in the calculated density is, after simplification

$$
\frac{\Delta \rho_{f}}{\rho_{f}}=\frac{A_{1} A_{2} t_{1} t_{2}\left(\rho_{s 1}-\rho_{s 2}\right)}{\left(A_{1} t_{2} \rho_{s 1}-A_{2} t_{1} \rho_{s 2}\right)\left(A_{1} t_{2}-A_{2} t_{1}\right)}\left(x_{1}-x_{2}\right) .
$$

The relative error is therefore proportional to the difference of the two relative errors in A. However, the magnitude of the errors shown in Table 6 do not conclude that the errors were attributed to the coefficients $A_{1}$ and $A_{2}$.

In terms of fall times $t_{1}$ and $t_{2}$, the approach to take the relative error as

$$
\frac{\Delta \rho_{f}}{\rho_{f}}=\frac{A_{1} A_{2} t_{1} t_{2}\left(\rho_{s 1}-\rho_{s 2}\right)}{\left(A_{1} t_{2} \rho_{s 1}-A_{2} t_{1} \rho_{s 2}\right)\left(A_{1} t_{2}-A_{2} t_{1}\right)}
$$

rewritten as

$$
\frac{\Delta \rho_{f}}{\rho_{f}}=\frac{\left(\rho_{s 1}-\rho_{s 2}\right)}{\left(\left(\rho_{s 1} A_{1} t_{2} / A_{2} t_{1}\right)-\rho_{s 1}+\left(\rho_{s 2} A_{2} t_{1} / A_{2} t_{2}\right)-\rho_{s 2}\right)}
$$

with further simplification in which

$$
\frac{A_{1} t_{2}}{A_{2} t_{1}}=\frac{1-\left(\rho_{f} / \rho_{s 1}\right)}{1-\left(\rho_{f} / \rho_{s 2}\right)}
$$


TABLE 4: Experimental and published viscosity and density data for n-dodecane.

\begin{tabular}{|c|c|c|c|c|c|c|}
\hline $\begin{array}{l}\text { Pressure } \\
(\mathrm{MPa})\end{array}$ & $\begin{array}{c}\rho_{f}(\text { calculated }) \\
\left(\mathrm{kg} \cdot \mathrm{m}^{-3}\right)\end{array}$ & $\begin{array}{c}\rho_{f} \\
\left(\mathrm{~kg} \cdot \mathrm{m}^{-3}\right)\end{array}$ & $\begin{array}{l}\text { Error } \\
(\%)\end{array}$ & $\begin{array}{c}\mu \text { (calculated }) \\
(\mathrm{mPa} \cdot \mathrm{s})\end{array}$ & $\begin{array}{c}\mu \\
(\mathrm{mPa} \cdot \mathrm{s})\end{array}$ & $\begin{array}{c}\text { Error } \\
(\%) \\
\end{array}$ \\
\hline 14.5 & 722.5 & 758.7 & -4.77 & 1.742 & 1.761 & -1.06 \\
\hline 20.3 & 834.5 & 762.4 & 9.47 & 1.82 & 1.877 & -3.01 \\
\hline 24.3 & 1075.3 & 764.8 & 40.61 & 1.804 & 1.96 & -7.97 \\
\hline 31.2 & 610.4 & 768.8 & -20.61 & 2.145 & 2.111 & 1.62 \\
\hline 35.2 & 588.5 & 771 & -23.67 & 2.254 & 2.201 & 2.39 \\
\hline 39.7 & 656.3 & 773.5 & -15.15 & 2.348 & 2.305 & 1.87 \\
\hline 45.2 & 659.5 & 776.4 & -15.06 & 2.48 & 2.439 & 1.68 \\
\hline 49.9 & 741.5 & 778.8 & -4.80 & 2.555 & 2.558 & -0.13 \\
\hline 54.5 & 1000.4 & 781.1 & 28.06 & 2.549 & 2.678 & -4.81 \\
\hline 59.8 & 903.1 & 783.7 & 15.24 & 2.759 & 2.821 & -2.20 \\
\hline 64.8 & 931.5 & 786.1 & 18.50 & 2.877 & 2.962 & -2.86 \\
\hline 70.4 & 889 & 788.6 & 12.72 & 3.056 & 3.124 & -2.18 \\
\hline 75 & 862.6 & 790.7 & 9.10 & 3.249 & 3.264 & -0.46 \\
\hline 81 & 867.2 & 793.4 & 9.30 & 3.399 & 3.456 & -1.66 \\
\hline 85.9 & 759.5 & 795.5 & -4.53 & 3.685 & 3.617 & 1.89 \\
\hline 95.2 & 648.8 & 799.3 & -18.83 & 4.151 & 3.943 & 5.27 \\
\hline 115.1 & 703.1 & 807.1 & -12.89 & 4.9 & 4.719 & 3.84 \\
\hline 120.5 & 612.1 & 809.1 & -24.35 & 5.231 & 4.95 & 5.67 \\
\hline
\end{tabular}

TABle 5: Errors in coefficient A and evaluated properties for $n$ dodecane.

\begin{tabular}{lcccc}
\hline $\begin{array}{l}\text { Pressure } \\
(\mathrm{MPa})\end{array}$ & $\mathrm{A}_{1}$ & $\mathrm{~A}_{2}$ & $\rho_{f}$ & $\mu$ \\
\hline 14.5 & 1.62 & $(\%)$ & $(\%)$ & $(\%)$ \\
20.3 & 1.98 & 1.37 & -4.77 & -1.06 \\
24.3 & 3.57 & 0.78 & 40.61 & -3.01 \\
31.2 & 0.77 & 2.06 & -20.61 & -7.97 \\
35.2 & 0.36 & 1.84 & 23.67 & 2.62 \\
39.7 & -0.09 & 0.86 & -15.15 & 1.87 \\
45.2 & 0.09 & 1.05 & -15.06 & 1.68 \\
49.9 & 0.70 & 1.01 & -4.80 & -0.13 \\
54.5 & 1.57 & -0.35 & 28.06 & -4.81 \\
59.8 & 0.40 & -0.61 & 15.24 & -2.20 \\
64.8 & 0.68 & -0.57 & 18.50 & -2.86 \\
70.4 & 0.67 & -0.19 & 12.72 & -2.18 \\
75.0 & -0.63 & -1.24 & 9.10 & -0.46 \\
81.0 & 0.55 & -0.08 & 9.30 & -1.66 \\
85.9 & -1.32 & -1.02 & -4.53 & 1.89 \\
95.2 & -2.83 & -1.64 & -18.83 & 5.27 \\
115.1 & -2.18 & -1.34 & -12.89 & 3.84 \\
120.5 & -2.54 & -0.97 & -24.35 & 5.67 \\
\hline & & & &
\end{tabular}

gives a relative error of

$$
\frac{\Delta \rho_{f}}{\rho_{f}}=\frac{\left(\rho_{s 1}-\rho_{f}\right)\left(\rho_{s 2}-\rho_{f}\right)}{\left(\rho_{s 1}-\rho_{s 2}\right) \rho_{f}}\left(x_{1}-x_{2}\right) .
$$

In this case, to minimize the error in liquid density with respect to the liquid density in which

$$
\frac{d\left(\Delta \rho_{f} / \rho_{f}\right)}{\rho_{f}}=0
$$

gives $\rho_{f}=\sqrt{\rho_{s 1} \rho_{s 2}}$ suggesting that the liquid density should be the geometric mean of the two sinkers. Care should be taken with this result since it implies that one density should be less than that of the liquid thereby violating the phenomenon of buoyancy.

7.2. Viscosity. Again, it is worth noting that the errors between average value of $\mathrm{A}$ and experimental data are of great importance. The errors for A have been shown previously (Table 6) and are not large. The error transfer analysis was carried out to show how the errors between the average values of the two calibration coefficients and the corresponding experimental data which can affect the final error in viscosity determination. The basic condition is that the errors between the average and experimental data of A are not big.

The error analysis for viscosity determination is based on

$$
\mu=f\left(A_{1} A_{2}\right)=\frac{\rho_{s 2} t_{1} t_{2}-\rho_{s 1} t_{1} t_{2}}{\rho_{s 2} A_{2} t_{1}-\rho_{s 1} A_{1} t_{2}}
$$

in which the Taylor series expansion is

$$
\frac{\Delta \mu}{\mu}=\frac{\partial \ln f\left(A_{1}, A_{2}\right)}{\partial A_{1}} \Delta A_{1}+\frac{\partial \ln f\left(A_{1}, A_{2}\right)}{\partial A_{2}} \Delta A_{2},
$$


TABLE 6: Relative errors in calibration coefficients.

\begin{tabular}{lccc}
\hline $\begin{array}{l}\text { Pressure } \\
(\mathrm{MPa})\end{array}$ & $x_{1}$ & $x_{2}$ & $x_{1}-x_{2}$ \\
$(\%)$ & $(\%)$ & -0.31 \\
\hline 14.5 & 1.62 & 1.93 & 0.61 \\
20.3 & 1.98 & 1.37 & 2.79 \\
24.3 & 3.57 & 0.78 & -1.29 \\
31.2 & 0.77 & 2.06 & -1.48 \\
35.2 & 0.36 & 1.84 & -0.95 \\
39.7 & -0.09 & 0.86 & -0.96 \\
45.2 & 0.09 & 1.05 & -0.31 \\
49.9 & 0.7 & 1.01 & 1.92 \\
54.5 & 1.57 & -0.35 & 1.01 \\
59.8 & 0.4 & -0.61 & 1.25 \\
64.8 & 0.68 & -0.57 & 0.86 \\
70.4 & 0.67 & -0.19 & 0.61 \\
75 & -0.63 & -1.24 & 0.63 \\
81 & 0.55 & -0.08 & -0.3 \\
85.9 & -1.32 & -1.02 & -1.19 \\
95.2 & -2.83 & -1.64 & -0.84 \\
115.1 & -2.18 & -1.34 & -1.57 \\
120.5 & -2.54 & -0.97 & \\
\hline
\end{tabular}

where

$$
\begin{aligned}
& \frac{\partial \ln f\left(A_{1}, A_{2}\right)}{\partial A_{1}}=\frac{\rho_{s 1} t_{2}}{\left(\rho_{s 2} A_{2} t_{1}-\rho_{s 1} A_{1} t_{2}\right)}, \\
& \frac{\partial \ln f\left(A_{1}, A_{2}\right)}{\partial A_{1}}=\frac{\rho_{s 2} t_{2}}{\left(\rho_{s 2} A_{2} t_{1}-\rho_{s 1} A_{1} t_{2}\right)} .
\end{aligned}
$$

The largest possible relative error in the calculated density is, after simplification

$$
\frac{\Delta \mu}{\mu}=\frac{x_{1}-\left(\rho_{s 2} t_{1} A_{2} / \rho_{s 1} t_{2} A_{1}\right) x_{2}}{\left(\rho_{s 2} t_{1} A_{2} / \rho_{s 1} t_{2} A_{1}\right)-1} .
$$

Writing in the form of fluid density gives

$$
\frac{\Delta \mu}{\mu}=\frac{\left(\rho_{s 2}-\rho_{f}\right) x_{2}}{\rho_{s 1}-\rho_{s 2}}-\frac{\left(\rho_{s 1}-\rho_{f}\right) x_{1}}{\rho_{s 1}-\rho_{s 2}} .
$$

To minimize the error in which

$$
\frac{d\left(\Delta \mu_{f} / \mu_{f}\right)}{\rho_{f}}=0
$$

gives $1 /\left(\rho_{s 1}-\rho_{s 2}\right) \rightarrow 0$. This suggests that the widest possible difference in density is required.

\section{Conclusions}

It is possible to use the high pressure falling body sinker to determine the viscosity of liquid without the need for supplementary knowledge of liquid density data. Good agreement is found with determining the viscosity data although less so for the derived density data. There are inherent errors in this new approach which have been addressed. However, in order to ensure that the errors remain as small as possible, it is recommended that sinkers should be used, which exhibit good self centering properties. The radius ratio of the sinker to inner tube should be greater than 0.95 . Additionally, it is necessary to use two sinkers with a large difference in value of A to avoid inaccuracies. The density of the sinkers should be obviously greater than that of the liquid tested so that it is capable of descening although the bulk densities of the two sinkers should be sufficiently dissimilar.

\section{Nomenclature}

$a-e$ : Constant

A: $\quad$ Calibration coefficient $\left(\mathrm{Pa}^{-1}\right)$

$B: \quad$ Constant $(\mathrm{Pa})$

C: $\quad$ Constant $(-)$

g: Gravitational acceleration $\left(\mathrm{m} \cdot \mathrm{s}^{-2}\right)$

$L_{s}$ : Length of sinker $(\mathrm{m})$

$L_{t}$ : Distance between the centre of two detecting coils (m)

$L_{s 0}$ : Original length of the sinker $(\mathrm{m})$

$L_{t 0}$ : Distance between two detecting coils $(\mathrm{m})$

$m_{s}$ : Mass of sinker $(\mathrm{kg})$

$M: \quad$ Molecular weight $\left(\mathrm{kg} \cdot \mathrm{mol}^{-1}\right)$

$P: \quad$ Pressure $(\mathrm{Pa})$

$P_{0}: \quad$ Reference pressure $(\mathrm{Pa})$

$r_{2}$ : Inner radius of tube $(\mathrm{m})$

$r_{1}: \quad$ Radius of sinker $(\mathrm{m})$

$R$ : Parameter

$\mathrm{Re}_{m}$ : Modified Reynolds number (-)

$t: \quad$ Falling duration of the sinker (s)

$T: \quad$ Temperature $(\mathrm{K})$

$T_{0}$ : Reference temperature (K)

$u$ : Parameter

$v: \quad$ Terminal velocity $\left(\mathrm{m} \cdot \mathrm{s}^{-1}\right)$

$V$ : Molar volume

$V_{o}$ : Molar core volume

$x$ : $\quad$ Relative error (\%).

\section{Greek}

$\alpha$ : Thermal expansion coefficient $\left(\mathrm{K}^{-1}\right)$

$\beta$ : Compressibility of the sinker $\left(\mathrm{MPa}^{-1}\right)$

$\mu$ : Viscosity of fluid $(\mathrm{Pa} \cdot \mathrm{s})$

$\mu^{*}$ : Dimensionless viscosity $(-)$

$\rho_{f}$ : Density of fluid $\left(\mathrm{kg} \cdot \mathrm{m}^{-3}\right)$

$\rho_{o}$ : Reference density $\left(\mathrm{kg} \cdot \mathrm{m}^{-3}\right)$

$\rho_{s}$ : Density of sinker $\left(\mathrm{kg} \cdot \mathrm{m}^{-3}\right)$.

\section{Subscript}

1: Sinker 1

2: Sinker 2. 


\section{References}

[1] M. R. Riazi and G. N. Al-Otaibi, "Estimation of viscosity of liquid hydrocarbon systems," Fuel, vol. 80, no. 1, pp. 27-32, 2001.

[2] N. A. Park and T. F. Irvine Jr., "Measurements of rheological fluid properties with the falling needle viscometer," Review of Scientific Instruments, vol. 59, no. 9, pp. 2051-2058, 1988.

[3] N. A. Park and T. F. Irvine Jr., "The falling needle viscometer a new technique for viscosity measurements," Wärme-und Stoffübertragung, vol. 18, no. 4, pp. 201-206, 1984.

[4] M. Brizard, M. Megharfi, E. Mahé, and C. Verdier, "Design of a high precision falling-ball viscometer," Review of Scientific Instruments, vol. 76, no. 2, Article ID 025109, 6 pages, 2005.

[5] J. H. Dymond, K. J. Young, and J. D. Isdale, “Transport properties of nonelectrolyte liquid mixtures-II. Viscosity coefficients for the $n$-hexane $+n$-hexadecane system at temperatures from 25 to $100^{\circ} \mathrm{C}$ at pressures up to the freezing pressure or $500 \mathrm{MPa}$," International Journal of Thermophysics, vol. 1, no. 4, pp. 345-373, 1980.

[6] J. B. Irving and A. J. Barlow, "An automatic high pressure viscometer," Journal of Physics E, vol. 4, no. 3, pp. 232-236, 1971.

[7] H.-P. Mattischek and R. Sobczak, "New cell for measurement of viscosity under high pressure," Measurement Science and Technology, vol. 5, no. 7, pp. 782-785, 1994.

[8] S. C. Vant, Investigation of fluid properties at non-ambient conditions, Ph.D. thesis, Department of Chemical and Process Engineering, University of Strathclyde, Glasgow, UK, 2003.

[9] Z.-S. Sha, "The improvement on the falling needle viscometer," Review of Scientific Instruments, vol. 68, no. 4, pp. 18091811, 1997.

[10] A. M. J. Davis and H. Brenner, "The falling-needle viscometer," Physics of Fluids, vol. 13, no. 10, pp. 3086-3088, 2001.

[11] A. Kumagai, Y. Kawase, and C. Yokoyama, "Falling capillary tube viscometer suitable for liquids at high pressure," Review of Scientific Instruments, vol. 69, no. 3, pp. 1441-1445, 1998.

[12] C. Boned, C. K. Zéberg-Mikkelsen, A. Baylaucq, and P. Daugé, "High-pressure dynamic viscosity and density of two synthetic hydrocarbon mixtures representative of some heavy petroleum distillation cuts," Fluid Phase Equilibria, vol. 212, no. 1-2, pp. 143-164, 2003.

[13] A. Allal, M. Moha-Ouchane, and C. Boned, "A new free volume model for dynamic viscosity and density of dense fluids versus pressure and temperature," Physics and Chemistry of Liquids, vol. 39, no. 1, pp. 1-30, 2001.

[14] M. M. Aalto and K. I. Keskinen, "Liquid densities at high pressures,” Fluid Phase Equilibria, vol. 166, no. 2, pp. 183-205, 1999.

[15] V. N. Belonenko, V. M. Troitsky, Y. E. Belyaev, J. H. Dymond, and N. F. Glen, "Application of a micro-(p, V, T) apparatus for measurement of liquid densities at pressures up to $500 \mathrm{MPa}$," Journal of Chemical Thermodynamics, vol. 32, no. 9, pp. 12031219, 2000.

[16] E. Kiran and Y. L. Sen, "High-pressure viscosity and density of n-alkanes," International Journal of Thermophysics, vol. 13, no. 3, pp. 411-442, 1992.

[17] H. Korsten, "Critical properties of hydrocarbon systems," Chemical Engineering and Technology, vol. 21, no. 3, pp. 229244, 1998.

[18] C. J. Schaschke, S. Allio, and E. Holmberg, "Viscosity measurement of vegetable oil at high pressure," Food and Bioproducts Processing, vol. 84, no. 3, pp. 173-178, 2006.
[19] J. B. Irving, "The effect of nonvertical alignment on the performance of a falling-cylinder viscometer," Journal of Physics D, vol. 5, no. 1, pp. 214-224, 1972.

[20] N. D. Cristescu, B. P. Conrad, and R. Tran-Son-Tay, "A closed form solution for falling cylinder viscometers," International Journal of Engineering Science, vol. 40, no. 6, pp. 605-620, 2002.

[21] C. J. Schaschke, S. Abid, I. Fletcher, and M. J. Heslop, "Evaluation of a falling sinker-type viscometer at high pressure using edible oil," Journal of Food Engineering, vol. 87, no. 1, pp. 51-58, 2008.

[22] E. G. Wehbeh, T. J. Ui, and R. G. Hussey, "End effects for the falling cylinder viscometer," Physics of Fluids A, vol. 5, no. 1, pp. 25-33, 1992.

[23] J. F. Stalnaker and R. G. Hussey, "Wall effects on cylinder drag at low Reynolds number," Physics of Fluids, vol. 22, no. 4, pp. 603-613, 1979.

[24] T. Lommatzsch, M. Megharfi, E. Mahe, and E. Devin, "Conceptual study of an absolute falling-ball viscometer," Metrologia, vol. 38, no. 6, pp. 531-534, 2001.

[25] P. Y. Huang and J. Feng, "Wall effects on the flow of viscoelastic fluids around a circular cylinder," Journal of Non-Newtonian Fluid Mechanics, vol. 60, no. 2-3, pp. 179-198, 1995.

[26] G. H. Ristow, "Wall correction factor for sinking cylinders in fluids," Physical Review E, vol. 55, no. 3, pp. 2808-2813, 1997.

[27] N. A. Park and T. F. Irvine Jr., "Falling cylinder viscometer end correction factor," Review of Scientific Instruments, vol. 66, no. 7, pp. 3982-3984, 1995.

[28] F. Gui and T. F. Irvine Jr., "Theoretical and experimental study of the falling cylinder viscometer," International Journal of Heat and Mass Transfer, vol. 37, supplement 1, pp. 41-50, 1994.

[29] D. R. Caudwell, J. P. M. Trusler, V. Vesovic, and W. A. Wakeham, "The viscosity and density of n-dodecane and noctadecane at pressures up to $200 \mathrm{MPa}$ and temperatures up to $473 \mathrm{~K}$," International Journal of Thermophysics, vol. 25, no. 5, pp. 1339-1352, 2004. 

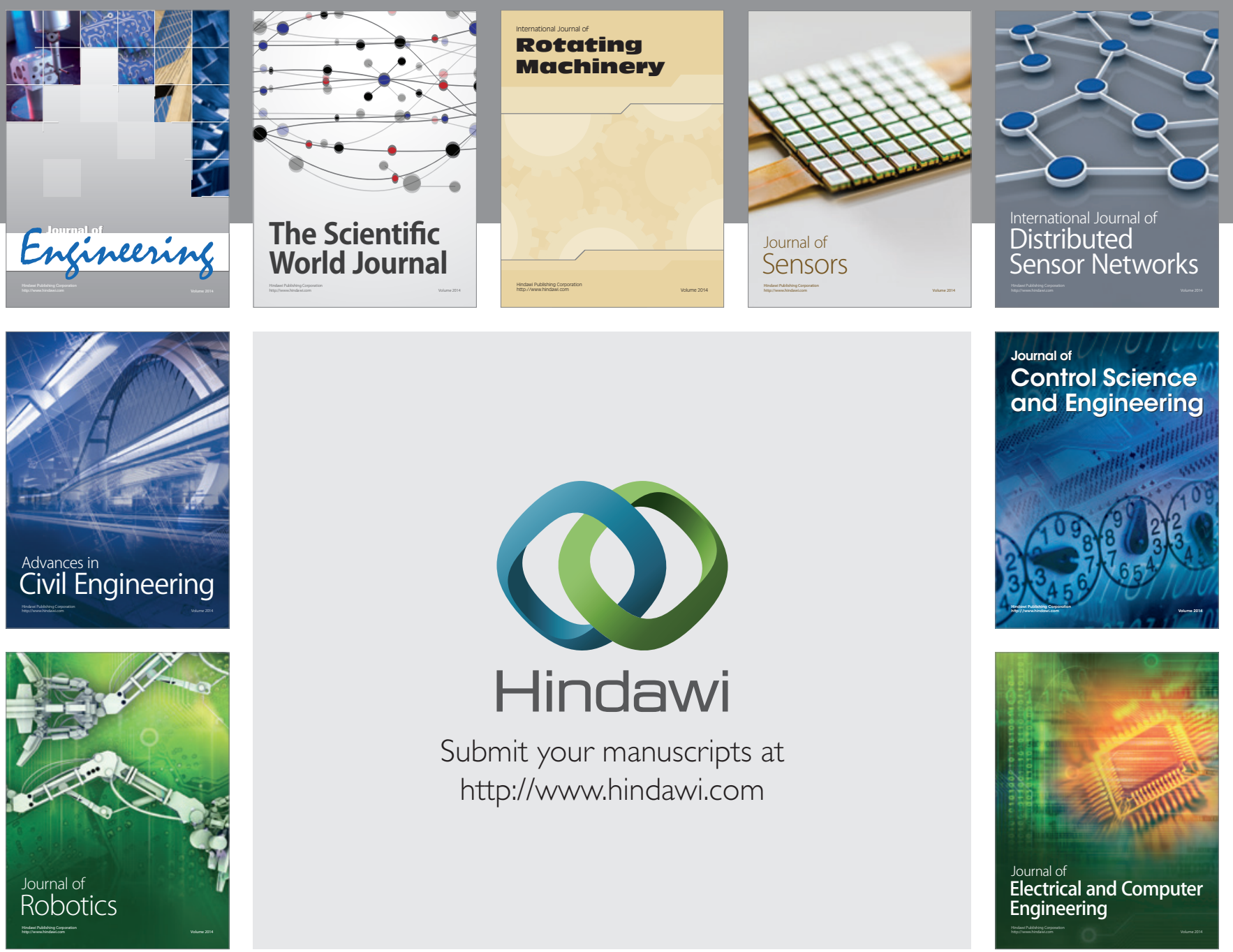

Submit your manuscripts at

http://www.hindawi.com
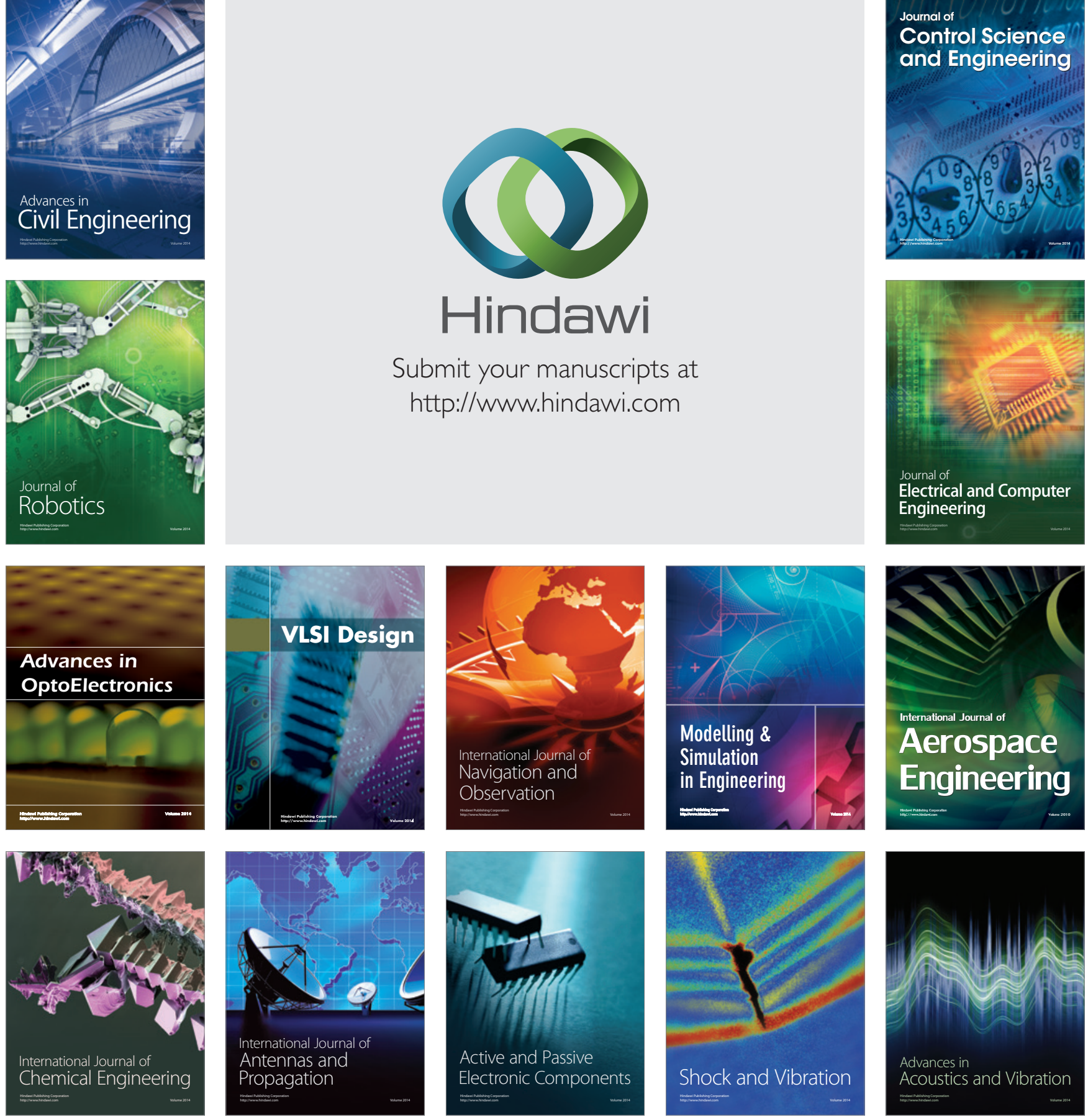